\title{
Patient's Intention to Use Mobile Health App
}

\author{
Tung Siaw Yee \\ Faculty of Business, Economics and Accounting and Economic \\ HELP University, 50490 Kuala Lumpur, Malaysia \\ E-mail: sylvietung@gmail.com \\ Lim Chui Seong \\ Faculty of Business, Economics and Accounting and Economic \\ HELP University, 50490 Kuala Lumpur, Malaysia \\ E-mail: chuiseong.lim@help.edu.my \\ Wong Siew Chin
}

Faculty of Business, Economics and Accounting and Economic

HELP University, 50490 Kuala Lumpur, Malaysia

E-mail: sc.wong@help.edu.my

$\begin{array}{lcc}\text { Received: March 14, } 2019 & \text { Accepted: May 27, } 2019 & \text { Published: July 1, } 2019 \\ \text { doi:10.5296/jmr.v11i3.14776 } & \text { URL: https://doi.org/10.5296/jmr.v11i3.14776 }\end{array}$

\begin{abstract}
The purpose of this paper is to examine the factors that influence the intention of patients to adopt mobile health apps. The factors selected to conduct this study are perceived usefulness, perceived ease of use, and subjective norm. The proposed research model was reviewed and validated using the PLS-SEM with a sample of 300 respondents. The results of this study showed that perceived usefulness, perceived ease of use, and subjective norm could positively affect the patient's intention to use the mobile health app. The results of this study have made it possible to fill the research gap and provide adequate statistical support to the future expansion of research in the field of mobile health app. For practical reasons, these results have also provided researchers, app developers and healthcare providers with valuable information on how to evaluate and develop effective mobile health apps from the users' perspective.
\end{abstract}

Keywords: Perceived Usefulness, Perceived Ease of Use, Subjective Norm 


\section{Introduction}

The use of mobile technology has increased at a tremendous pace. The smartphone users worldwide is at 1.46 billon for the year 2018 (PressReader, 2018). This rapid growth and advancement in mobile technology have provided many amenities that benefit the user and encourage the development of various mobile apps (Harrison et al., 2013). Specifically, in 2017, more than 325,000 health and medical apps were available on the Google Play Store and Apple App Store (Research2Guidance, 2017).

In general, mobile apps refer to software programs run by the US Food and Drug Administration, FDA (FDA 2018) on smartphones and other mobile communication devices. Mobile apps serve as accessories or software connected to a smartphone or other mobile communication devices. While, mobile health, known as "mHealth", is generally known as medical or public health practice supported by mobile devices (Tomlinson et al., 2013). In this research, the mobile devices to which the researcher refers are the handheld smartphone. In accordance with the basic definition of the mobile app, mobile app for health, as the name suggests, is the accessory or software associated with a smartphone, which provides users with supportive health or medical-related functions (Yasini and Marchand, 2015).

There are many types of health-related mobile apps available on the market, ranging from simple fitness and wellness apps to sophisticated apps providing diagnostic and treatment services (Albrecht, 2016). According to research2guidance (2016), mobile health apps can be categorized as follows: 
Table 1. The Categories of Mobile Health Apps (Research2guidance, 2016).

\begin{tabular}{|c|c|}
\hline Categories & Description \\
\hline $\begin{array}{l}\text { Remote } \\
\text { monitoring }\end{array}$ & $\begin{array}{l}\text { Monitoring a patient's health condition via remote telecommunication, } \\
\text { which includes lifescans for diabetes patients to monitor their blood } \\
\text { glucose level, remote heart monitoring, and other telehealth monitoring } \\
\text { services) }\end{array}$ \\
\hline $\begin{array}{l}\text { Diagnostic } \\
\text { apps }\end{array}$ & $\begin{array}{l}\text { These apps enable the accessibility of personal health record (PHR), } \\
\text { including digital imaging (MRI/X-ray), electronic charts and lab test } \\
\text { results, and enable symptoms check-up. }\end{array}$ \\
\hline $\begin{array}{l}\text { Remote } \\
\text { consultation }\end{array}$ & $\begin{array}{l}\text { Consultation, diagnosis or treatment via remote telecommunications that } \\
\text { remove the hinder of distance, such as connecting patients with a doctor via } \\
\text { video. }\end{array}$ \\
\hline $\begin{array}{l}\text { Patient } \\
\text { health } \\
\text { record }\end{array}$ & Enable patients to view their medical record via the smartphone health app. \\
\hline $\begin{array}{l}\text { Healthy } \\
\text { lifestyle } \\
\text { maintenance } \\
\text { apps }\end{array}$ & $\begin{array}{l}\text { Including pregnancy and baby development app, diet and nutrition app, } \\
\text { weight loss, menstrual period tracking app, and fitness tracking app. }\end{array}$ \\
\hline $\begin{array}{l}\text { Reminders } \\
\text { and alerts }\end{array}$ & $\begin{array}{l}\text { Enable patients to manage their prescriptions and appointments with health } \\
\text { care providers. }\end{array}$ \\
\hline $\begin{array}{l}\text { Medical } \\
\text { compliance } \\
\text { app }\end{array}$ & An app that manages patient medication and prescription adherence. \\
\hline
\end{tabular}

This study includes all of the above categories in the multiple selections of the questionnaire to determine the most used categories of mobile health apps among respondents. The results showed that the majority of respondents are currently using healthy lifestyle maintenance apps, followed by reminders and alerts medical apps.

The use of the mobile health app takes precedence over the traditional health process in terms of aspects of data collection, care delivery, patient engagement, and real-time drug monitoring 


\section{Al Macrothink}

Journal of Management Research

ISSN 1941-899X

2019, Vol. 11, No. 3

(Tomlinson et al., 2013). There are increasing number of patients who have begun to use their mobile health app to monitor and improve their health and wellness quality. These patients have a sense of responsibility for following the diet and medication prescribed by the health care provider, adhering to exercise routines and follow-up appointments (Gruessner, 2015).

Most importantly, the use of the mobile health app allows the user to access his or her desired health-related functions without having to travel long distances. In summary, the mobile health app has facilitated the medical and the health treatment process in a very accessible and cost-effective manner (Jones and Moffitt, 2016).

In addition, mobile apps not only work as a standalone item, but many upcoming mobile apps also integrate with peripheral devices. These apps leverage the ability of smart devices to synchronize with other devices or systems via Bluetooth (Hanrahan et al., 2014). Patient information will be collected and recorded in a central database that health professionals will be able to access on a regular basis (Athenahealth, 2018).

Despite the growing phenomenon of mobile health apps, there are still patients who have stopped using them after a while, who are opposed to the use of health apps or who are not even aware of the existence of such apps (Peng et al., 2016).

\section{Literature review}

\subsection{Perceived usefulness (PU)}

The perceived usefulness (PU), according to Davis (1989), is defined as the degree to which a person thinks that a given technology or information system could improve their performance at work. The individual will assess the benefit or value of the mobile health app in terms of the desired outcomes it could gain from adoption. In the context of this study, perceived usefulness is the degree to which users' perceptions of the health-related services offered by mobile health apps will be beneficial to them (Alloghani et al., 2015).

Legris et al. (2003) suggest that PU is usually measured using four elements: effectiveness, productivity, performance and overall usefulness of new technology. For example, physicians and patients will be more likely to adopt a mobile health app if they perceive that the app would be useful enough to effectively manage health care, improve their productivity and performance at work (Alloghani et al., 2015).

The word "perceived" usefulness is used because the user is based on his or her subjective thinking about whether the app is able to improve its performance and productivity (Price et al., 2012), while the degree of usefulness may differ from each other. In short, a patient will increase his chances of adopting mobile health apps as he has been able to take advantage of the benefits of these apps. For example, the app will be seen as useful if it allows users to improve their health management effectiveness or help users get drug updates and first-hand information. When patients perceive apps as useful for their health care outcomes, positive attitudes towards the app are created and result in a positive behavioral intention to use (Deng et al., 2012). 


\subsection{Perceived ease of use}

The perceived ease of use (PEOU), according to Davis (1989), is defined as the degree to which a patient believes in the use of a particular technology would require no effort. However, regardless of the usefulness of a given technology, the patient's intention to use will diminish when the mobile health app is too complex to exploit or the efforts devoted to its use outweigh the benefits of using it. Conversely, a patient will increase the desire or likelihood of adopting a new system when he feels that the system is comfortable, easy to use, and likely to use an app perceived to be easier to use than another. Grudin (1992) suggests that usability and usefulness should be treated separately. In general, PEOU can be described as "usability" because it describes the ease with which a user can perform a particular task. In other words, a usable system should be easy to learn and manipulate. In addition, ease of use also refers to the usability and suitability of a system (Zahra et al., 2017).

TAM has been widely used in studies of technology acceptance to predict users' intention to adopt a mobile health app (Dou et al., 2017; Sun et al., 2013). Sun et al. (2013) formulated a model combining TAM theory with other models to explain consumers' acceptance of health technology (Sun et al., 2013); Hung and Jen also applied the TAM model to assess the students' intention to use mobile technology to manage their personal health (Hung and Jen, 2012). In general, if patients believe that the particular mobile health app is easy to use and is able to effectively manage their health, it will increase their chances of adopting the technology. Therefore, PEOU is more related to the "hedonic" or "usability" orientation, which concerns the user experience. To operationalize the perceived ease of use in this research, reference is made to a mobile health app that requires is effortless to use, easy to learn to use and whose user experience is satisfied by patients.

\subsection{Subjective norm}

The subjective norm that can influence the behavioural intent of the patient. In general, the subjective norm refers to an individual's perception of who is important to a patient, whether or not he should adopt the behavior in question. In other words, the particular behaviour will be influenced by the judgment imposed by significant others (Ajzen, 1991, Fishbein and Ajzen, 1975, Venkatesh et al., 2003).

Subjective Norm is important because it reflects how the behavioural intent of patients is influenced by the judgment or perception of people that are important to patients (Sun et al., 2013). Specially designed for the adoption of mobile health apps, it is believed that the intention of patients to use the app will depend greatly on the important others' suggestion, especially healthcare professionals as well as friends or relatives who recommend it to patients. The reason for the subjective norm on behavioral intention is that people will be more likely to adopt a particular behavior when the behavior is recommended by people who are important referents, even if the behaviors are not favored by the patients' belief structure, but patients are sufficiently motivated to conform to referees' perception if they think they need to adopt certain behaviours (Deng et al., 2014; Dou et al., 2017).

In short, for the subjective norms that are operational in this study, the subjective norm refers to 


\section{Macrothink}

Journal of Management Research

ISSN 1941-899X

2019, Vol. 11, No. 3

the degree of perception by a patient with people who are important to him, such as his parents, close friends, relatives or professionals, think that he should or should not use the mobile health app.

\subsection{Behavioural Intentions}

Behavioural intention refers to the conscious plans of an individual or the likelihood that a person will perform a certain behavior or not. Behavior in this study refers to whether or not a patient adopts the mobile health app (Nasir and Yurder, 2015).

The behavioral intention to adopt a new technology is a dependent variable widely used in most research related to the acceptance of new technologies. Typically, this is a measurement variable designed to examine the intention to quickly adopt new technology or the continued use of a technology (Dou et al., 2017). In this current study, the concern for behavioral intention to use is seen as the intention of patients who were previously non-users to use the mobile health app, as well as the intention of adopters to continue to use the mobile health app. This behavioral intention is the dependent variable in this study, which will be influenced by independent variables, which are the factors stated in TAM (Perceived Usefulness, Perceived Ease of Use, and Subjective norm).

Therefore, the hypothesis of this study are as follows:

H1: Perceived usefulness has a positive effect on patients' intention to use the mobile health app.

H2: Perceived ease of use has a positive effect on patients' intention to use the mobile health app.

H3: The subjective norm has a positive effect on the intention of patients to use the mobile health app.

\section{Research framework}

\section{$\underline{\text { Independent Variables }} \quad \underline{\text { Dependent Variable }}$}

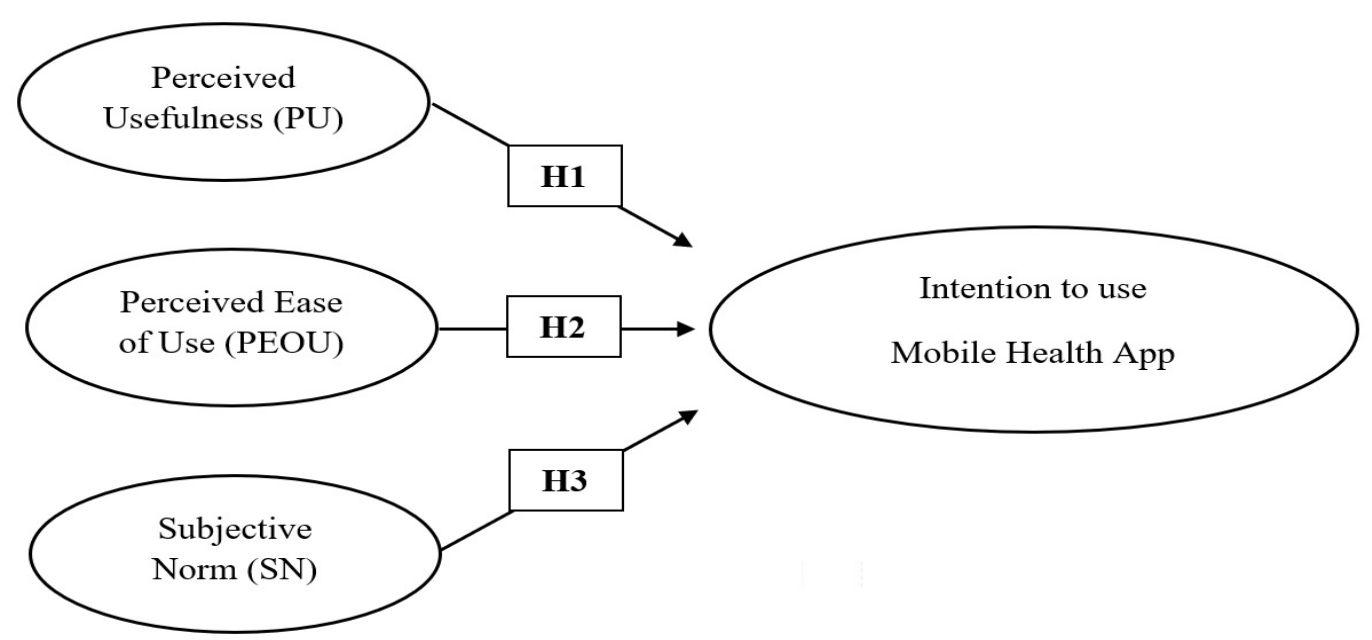

Figure 1. Research Framework 


\section{Methodology}

\subsection{Population and sample}

A total of 300 patients responded to the survey. $58.7 \%$ of them are female and $41.3 \%$ are male. The majority of respondents (37.7\%) were between the ages of 21 and 30, followed by $18.7 \%$ of respondents between the ages of 31 and 40, and $16 \%$ of the respondents were aged 20 and below. In addition, $13.7 \%$ of them are between 41 and 50 years old, $10.7 \%$ are between 51 and 60 years old, while the least frequency age group is 61 years and above, that is $3.3 \%$.

\subsection{Research Instruments}

All measurement items have been adapted and taken from previous studies, as previous researchers investigated the measurable constructs, resulting in a valid and more reliable result and fewer errors. While the adaptation of the measurement scale should strictly adhere to the rule of measurement selection, which should also reflect the definition of the constructs, the measurements should have an acceptable coefficient alpha (more than 0.7) indicating the reliability of the measurements, and finally the measurement must have multi-items to increase its reliability (Churchill Jr, 1979). All measurements for each construct are adapted from the original study and then adapted to the context of this research. In this study, a 7-point Likert scale was used for all adopted measures. The respondents rated each of the items from scale 1 (strongly disagree) to 7 (strongly agree). A higher scale of points may result in greater variance, which increases the reliability of the scale (Churchill Jr and Peter, 1984). The six items in PU and the six items in PEOU were adapted for the current study of Davis (1989); five (5) subjective norm (SN) items were adapted from Nor et al. (2008) and four items intention to use, have been adapted from Kang (2014). All had Cronbach's alpha greater than 0.8.

\subsection{Data analysis}

The data were entered into SPSS and then transmitted to SmartPLS for analysis. Convergent validity and discriminant validity were used to analyse the measurement model before proceeding with the analysis of the structured model.

Convergence validity is a measure of checking whether the correlations of multiple items of the same construct are in agreement or measuring the degree to which a measurement item is positively correlated with another within the same construct (Ringle et al., 2005). The average variance extracted (AVE) is the indicator used to measure convergent validity. An AVE value greater than 0.5 indicates that more than half of the indicators can be explained by its construct; conversely, if the AVE value is less than 0.5, this means that additional errors still remain in the elements of the construct (Hair et al., 2014). According to Bagozzi and Yi (1988), the AVE value should be greater than 0.5 to achieve adequate convergent validity. Table 2 shows that all AVE values were greater than 0.5 ; the convergent validity is therefore confirmed and accepted.

Discriminant validity refers to the extent to which the construct is distinct from another constructed empirically. It is also a measure used to examine the correlation between concepts, their potential for overlap (Hair et al., 2014, Ramayah et al., 2018). The discriminant validity is accessible via the Fornell-Lacker criterion. The logic of this method is that a construct should 
be able to explain its own variance better than the variance of other constructs (Ramayah et al., 2018). The Fornell-Lacker criterion is measured by comparing the square root of the average variance extracted (AVE) with the correlation of latent variables. The square root of the AVE for each variable must be greater than its correlations with other latent variables (Hair et al., 2014). Table 3 shows that all constructs describe an AVE square root value greater than that of other associated constructs. Therefore, the discriminant validity of the constructs is adequate.

Another measure of discriminant validity is the Heterotrait-monotrait (HTMT) correlation ratio proposed by Henseler et al. (2015). HTMT is a stricter method for evaluating the correlation between constructs. Henseler et al. (2015) suggested that HTMT could achieve relatively higher specificity and sensitivity rates, $97 \%$ to $99 \%$, compared to cross-loadings criterion $(0.00 \%)$ and Fornell-Lacker (20.82\%) (Ramayah et al., 2018). If the HTMT values of two constructs are close to 1, this indicates a lack of discriminant validity; conversely, if the HTMT value is less than 1, this means that the two constructs are empirically distinct (Ramayah et al., 2018). While Kline (2011) suggested that the threshold for the HTMT should be 0.85 and that Gold et al. (2001) suggested 0.90 if the value of HTMT is above this threshold, it can be concluded that there is a problem of discriminant validity. Table 4 shows that the HTMT values between all constructs are less than 1 , which means that the discriminant validity is sufficient and that all constructs differ from each other. 
Table 2. The result of the measurement model

\begin{tabular}{|c|c|c|c|c|c|}
\hline Construct & Items & $\begin{array}{l}\text { Outer } \\
\text { Loading }\end{array}$ & $\begin{array}{l}\text { Average } \\
\text { Variance } \\
\text { Extracted } \\
\text { (AVE) }\end{array}$ & $\begin{array}{l}\text { Composition } \\
\text { Reliability } \\
\text { (CR) }\end{array}$ & $\begin{array}{l}\text { Cronbach's } \\
\text { Alpha (CA) }\end{array}$ \\
\hline \multirow{6}{*}{ Perceived Usefulness } & PU 1 & 0.855 & \multirow[t]{6}{*}{0.796} & \multirow[t]{6}{*}{0.959} & \multirow[t]{6}{*}{0.948} \\
\hline & PU 2 & 0.908 & & & \\
\hline & PU 3 & 0.913 & & & \\
\hline & PU 4 & 0.889 & & & \\
\hline & PU 5 & 0.877 & & & \\
\hline & PU 6 & 0.909 & & & \\
\hline \multirow{6}{*}{ Perceived Ease of Use } & PEOU 1 & 0.849 & \multirow[t]{6}{*}{0.749} & \multirow[t]{6}{*}{0.947} & \multirow[t]{6}{*}{0.933} \\
\hline & PEOU 2 & 0.838 & & & \\
\hline & PEOU 3 & 0.880 & & & \\
\hline & PEOU 4 & 0.883 & & & \\
\hline & PEOU 5 & 0.855 & & & \\
\hline & PEOU 6 & 0.887 & & & \\
\hline \multirow{5}{*}{ Subjective Norm } & SN 1 & 0.893 & \multirow[t]{5}{*}{0.873} & \multirow[t]{5}{*}{0.972} & \multirow[t]{5}{*}{0.964} \\
\hline & SN 2 & 0.946 & & & \\
\hline & SN 3 & 0.945 & & & \\
\hline & $\mathrm{SN} 4$ & 0.946 & & & \\
\hline & SN 5 & 0.941 & & & \\
\hline \multirow{4}{*}{ Behavioral Intention to Use } & BI 1 & 0.958 & \multirow[t]{4}{*}{0.906} & \multirow[t]{4}{*}{0.975} & \multirow[t]{4}{*}{0.965} \\
\hline & BI 2 & 0.961 & & & \\
\hline & BI 3 & 0.936 & & & \\
\hline & BI 4 & 0.952 & & & \\
\hline
\end{tabular}


Table 3. Discriminant Validity (Fornell-Larcker Criterion)

\begin{tabular}{|l|l|l|l|l|}
\hline & $\begin{array}{l}\text { Patients } \\
\text { intention to use }\end{array}$ & $\begin{array}{l}\text { Perceived } \\
\text { ease of use }\end{array}$ & $\begin{array}{l}\text { Perceived } \\
\text { usefulness }\end{array}$ & $\begin{array}{l}\text { Subjective } \\
\text { norm }\end{array}$ \\
\hline $\begin{array}{l}\text { Behavioral intention } \\
\text { to use }\end{array}$ & $\mathbf{0 . 9 5 2}$ & & & \\
\hline Perceived ease of use & 0.490 & $\mathbf{0 . 8 6 5}$ & & \\
\hline Perceived usefulness & 0.570 & 0.619 & $\mathbf{0 . 8 9 2}$ & \\
\hline Subjective norm & 0.617 & 0.403 & 0.446 & $\mathbf{0 . 9 3 4}$ \\
\hline
\end{tabular}

Table 4. Heterotrait-Monotrait Ratio (HTMT)

\begin{tabular}{|l|l|l|l|l|}
\hline & $\begin{array}{l}\text { Behavioral } \\
\text { intention to use }\end{array}$ & $\begin{array}{l}\text { Perceived } \\
\text { ease of use }\end{array}$ & $\begin{array}{l}\text { Perceived } \\
\text { usefulness }\end{array}$ & $\begin{array}{l}\text { Subjective } \\
\text { norm }\end{array}$ \\
\hline $\begin{array}{l}\text { Behavioral intention } \\
\text { to use }\end{array}$ & & & & \\
\hline Perceived ease of use & 0.511 & 0.659 & & \\
\hline Perceived usefulness & 0.595 & 0.422 & 0.465 & \\
\hline Subjective norm & 0.640 & & & \\
\hline
\end{tabular}

Table 5 and Figure 2 present the results of the postulated hypotheses. The $\mathrm{R}^{2}$ in this particular research is 0.50 , which is considered moderate. This indicates that the independent variables (perceived usefulness, perceived ease of use and subjective norm) may explain $50 \%$ of the variance of the dependent variable (intention of patients to use a mobile health app). Hypothesis $\mathrm{H} 1, \mathrm{H} 2$, and $\mathrm{H} 3$ are all supported at the $5 \%$ level of significance $(\alpha=0.05)$, with a t-value of 4,399 , 2,054 and 7,843 respectively. 


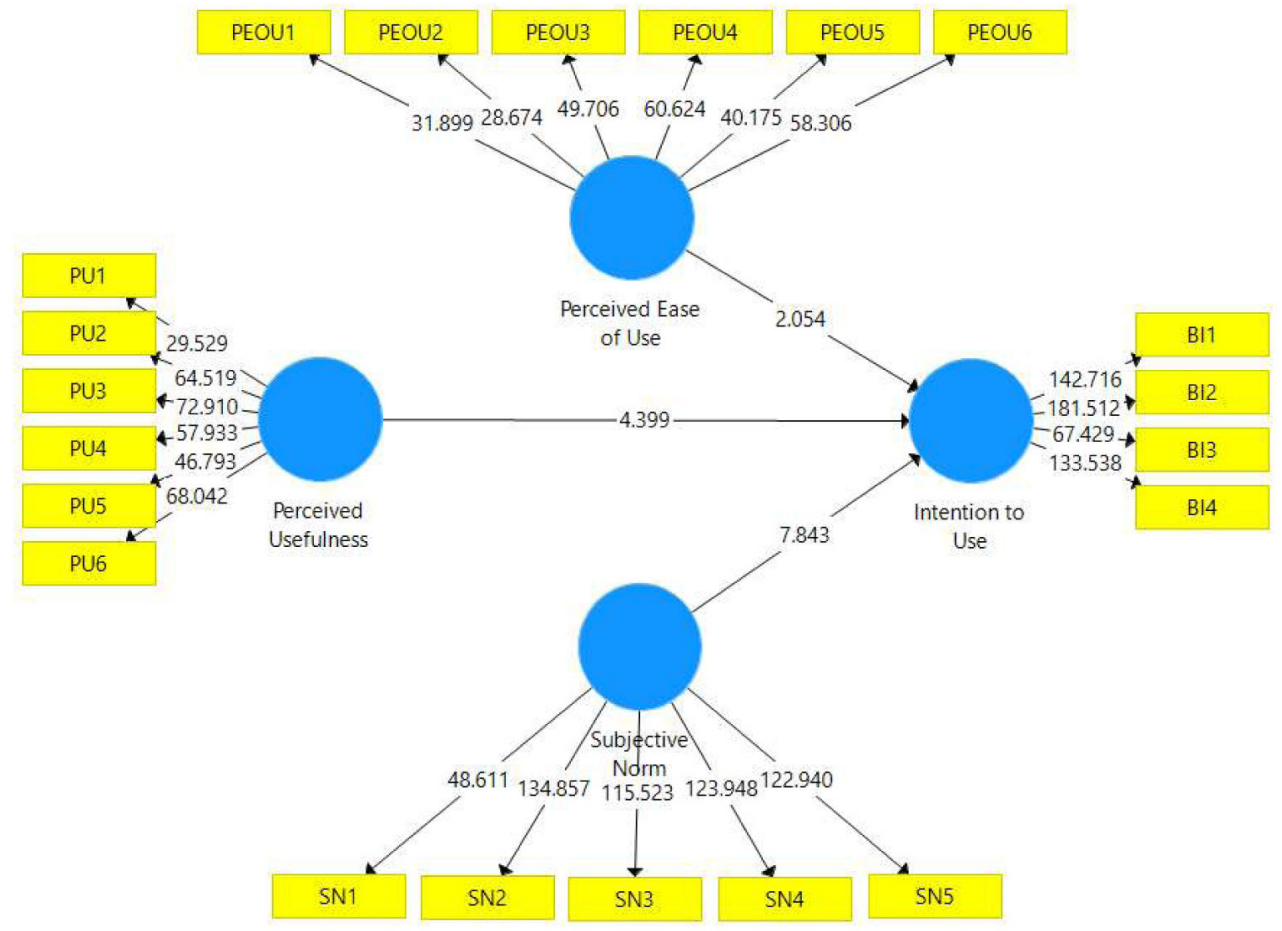

Figure 2. Results of Structural Model $(n=300$, bootstrapping subsample=5000)

Table 5. Results of Hypothesis Testing

\begin{tabular}{lllllll}
\hline Hypothesis & Constructs & $\begin{array}{c}\text { Sample } \\
\text { Mean }\end{array}$ & $\begin{array}{l}\text { Standard } \\
\text { Deviation }\end{array}$ & t-value & p-value & Decision \\
\hline H1 & PU -> BI & 0.293 & 0.067 & 4.399 & 0.000 & Supported \\
H2 & PEOU -> & & & & & \\
& BI & 0.137 & 0.065 & 2.054 & 0.020 & Supported \\
H3 & SN - B B & 0.431 & 0.055 & 7.843 & 0.000 & Supported \\
\hline
\end{tabular}

Note: $* * \mathrm{p}<.05$

Note: $\mathrm{BI}=$ Patients intention to use, $\mathrm{PEOU}=$ Perceived ease of use,

$\mathrm{PU}=$ Perceived usefulness, $\mathrm{SN}=$ Subjective norm

The effect size $\left(\mathrm{f}^{2}\right)$ is used to evaluate the relative impact of the independent variables on the dependent variable by excluding the predecessor variables and observing the change in the $\mathrm{R}^{2}$ value to estimate their significance (Cohen, 1988). Therefore, the effect size is defined as the difference of $\mathrm{R}^{2}$ values for the model with and without predecessor construct (Ramayah et al., 2018). If an independent variable can strongly explain the dependent variable, the difference between $\mathrm{R}^{2}$ is included and $\mathrm{R}^{2}$ is excluded, resulting in 
a high $\mathrm{f}^{2}$. According to Cohen (1988), $\mathrm{f}^{2}$ values above $0.35,0.15$ and 0.02 are considered to be large, medium and small effect sizes respectively. Based on the result shown in Table 6, the effect size of perceived ease-of-use and perceived usefulness with a corresponding $\mathrm{f}^{2}$ value of 0.021 and 0.099 is shown to be small, while a subjective norm with the $\mathrm{f}^{2}$ value of 0.289 has a medium effect on the model.

Table 6. The Effect Size $\left(\mathrm{f}^{2}\right)$

\begin{tabular}{|l|l|l|}
\hline Constructs & Effect Size $\mathrm{f}^{2}$ & Rank \\
\hline Perceived ease of use & 0.021 & small \\
\hline Perceived usefulness & 0.099 & small \\
\hline Subjective norm & 0.289 & medium \\
\hline
\end{tabular}

\section{Discussion}

Three hypotheses have been developed and tested via SmartPLS. Based on the findings of SmartPLS, it was shown that all hypotheses are supported and have a significant correlation. In order to examine the relationship between the perceived usefulness and the patient's behavioral intention to use the mobile health app, this hypothesis of perceived usefulness suggested in Hypothesis 1 has a positive effect on patients' intention to use the mobile health app. Based on the findings of SmartPLS, the result showed that the perceived usefulness actually has a significant positive relationship (t-value $=4,399, \alpha=0.05$, one-tailed test) with the patient's behavioral intention to use the mobile health app, $\mathrm{H} 1$ is therefore supported. This finding is in line with the findings of (Nasir and Yurder, 2015), (Deng et al., 2012) and (Alloghani et al., 2015) where the perceived usefulness has a positive effect on the patient's behavioral intention to use the mobile health apps. Patients will have a more positive attitude towards the mobile health app if the app is so useful that the user can effectively control their health care (Nasir and Yurder, 2015). More perceived usefulness leads to greater acceptance and a behavioral intention to adopt the mobile health app. Therefore, this study confirms that perceived usefulness is a critical factor in the patient's intention to use the mobile health app.

In order to examine the relationship between perceived ease of use and the patient's behavioral intention to use the mobile health app, this presumption of usability suggested in Hypothesis 2 has positively impacted the patient's positive effect on the patient's mobile health use. Based on the findings of SmartPLS, it has been shown that there is a significant correlation between the perceived ease-of-use and behavioral intention to use mobile health app (t-value $=2.054, \alpha=$ 0.05 , one-tailed test). Therefore, $\mathrm{H} 2$ is supported. This finding is in line with the findings of (Alloghani et al., 2015) and (Sun et al., 2013) who believe that the perceived ease of use is an important indicator that influences the intention to use the mobile health services. The interface design and features of the app are therefore important because the likelihood of app adoption for the patient increases when less effort is required, the operation is easy to learn, and satisfying user experience is possible. This study has confirmed that perceived ease of use can positively affect the patient's intention to use the mobile health app. 
In order to examine the relationship between subjective norm and the patient's intention to use the mobile health app, this hypothesis 3 proposed study suggests that subjective norm positively influences the patient's intention to use the mobile health app. Based on the findings of SmartPLS, there was a significant correlation between the subjective norm and the behavioral intent of Mobile Health App (t-value $=7,843, \alpha=0.05$, one-tailed test). Therefore, $\mathrm{H} 3$ is supported. The effect size $\left(\mathrm{f}^{2}\right)$ of the subjective norm is higher than the other two variables and therefore has a higher predictive relevance to the adoption intention. This finding is consistent with the finding of Sun et al. (2013), which suggest that the subjective norm is positively related to the adoption intention of the mobile health system. It states that patients are more likely to use mobile health apps if the people they trust most or care about, such as their parents, friends, relatives or professionals, think that they should adopt the particular app. The result confirms that patients have received the approval of their social environment through the use of the mobile health app.

\section{Implications}

A few studies have been conducted on the factors that influence the intention of adopting mobile health app, this research is able to fill the gap in the literature on this area, to enrich the existing literature on marketing by providing more information and knowledge to researchers.

The important features and benefits for $m$-health apps where the desired users will be examined. This study found that variables such as PU and PEOU are two important factors that have a significant association with the patient's intention to use the mobile health app. As a result, app developers, researchers, and health care providers may have first-hand data to present the desired health apps from the user's point of view, focused on both indicators. While software companies can better adapt to the barriers and technical weaknesses of mobile apps and continue to innovate product features to increase the adoption rate or reach a broader and more targeted user (Krebs and Duncan, 2015).

In addition, from a marketing perspective, the results of this research will help health companies understand the framework or key determinants that play an important role in the adoption process. Based on the results of this study, $\mathrm{SN}$ is considered to be the most important factor that can positively influence the patient's intention to adopt a mobile health app. As a result, business marketing decision makers need to conduct effective marketing campaigns such as promotional strategies to increase consumer favorable perception of apps, its rapid adoption, and market share expansion through social influence (for example, word of mouth) (Müller, 2013; Sun et al., 2013).

\section{Limitations and Future Suggestions}

Despite the theoretical and practical implications of the research, this study also presented several limitations that need to be addressed in future studies. Firstly, most of the samples collected for this study came from respondents in a city area. In this case, the results generated by these respondents may not fully represent the population.

In addition, the users' level of adoption of new technology may be different from country to country as well as the culture and the degree of acceptability will be different, even if the 
studies were based on commonly used TAM theory. For example, due to the diversity of cultural aspects, the PU can be considered as a key factor to be taken into account by Western Europeans in their decision to adopt the technology, as they may be more educated in health care than non-Western countries (e.g., Asian) (Beldad and Hegner, 2017).

Furthermore, demographic and lifestyle aspects have also contributed to a certain level of limitation. Of the respondents in this study, not all are concerned about their health. Their age can also have a huge impact on the adoption of mobile apps. For example, the PU may be considered insignificant by respondents who are less concerned about their health. Indeed, they may feel that mobile health apps do not improve the quality of their lives or be the patient who only needs health services from time to time. Therefore, whatever the usefulness of the health app, they will not appreciate it. In addition, compared to younger respondents, the behavioral intention of using mobile health apps among older respondents could be more significantly affected by PEOU. Therefore, future studies should consider changes in the sampled population or changes in variables that may affect outcomes (e.g., the role of PEOU may not be as important in younger patients).

\section{Recommendations}

The respondents aged 21 to 30 represented a significant proportion. Therefore, a preconceived idea can arise because the likelihood of respondents "agreeing" to use mobile health apps is high. Since the majority of early technology users are generally younger, they tend to want to use mobile health apps compared to older respondents (late majority and late adoption of technology) (Nielsen Global Survey, 2015). Therefore, in order to obtain more accurate and unbiased results, future research should include more elderly people in the sample of this study because they are more likely to be concerned about their health and represent the proportion of mobile health system users (Sun et al., 2013).

In addition, the model in this study has only $50 \%$ explanatory power, indicating that only $50 \%$ of the variance in the patient's behavioral intention to adopt a mobile health app can be explained by the variables associated with it. This shows that the variables embedded in this current research model may not be sufficient to provide a complete picture of the intention to adopt a mobile health app. More variables should be included in future studies, such as mobile self-efficacy, risk perception, as well as other demographic factors (e.g., level of education, experience, and cultural factors) (Faqih and Jaradat, 2015). Future analysis could be more reliable and precise in addressing these limitations and in adopting these recommendations.

In terms of perceived Usefulness (PU), the app developer must emphasize the usefulness of the app in question to improve patient outcomes in health care. In this case, the patient's health could be managed more efficiently. The usefulness of the app is the functionality or the utility aspect, like the functionality of the app itself. As proposed by Davis (1989), Perceived Ease of Use (PEOU) is also a key dimension to consider when adopting new technologies. If apps are user-friendly, patients will be more likely to adopt mobile health apps. Indeed, it allows them to understand and operate with minimal effort. In addition, Behavioral Intention (BI) may also be affected by the subjective norm (SN), in which patients would have the positive intention of adopting the mobile health app if they obtain social approval or positive recommendation of 
people who are important to them.

\section{Conclusion}

The main objective of this study is to study the factors that influence the intention of patients to adopt mobile health apps. Perceived Usefulness, perceived ease of use and subjective norms are the factors selected for this study. Based on the analysis of data generated from 300 data via SmartPLS, the statistical results indicate that these three factors have a significant positive relationship with the intention of patients to use the mobile health app.

By understanding the factors that have a significant impact on intention to use, healthcare providers and app developers will gain general insights into the development of successful mobile health apps. In addition, this study also benefits business investors, marketers, and healthcare sector. They are able to establish a more effective plan and decision as this research provided patients' perspective on mobile health apps.

Summarily, patients generally have a positive attitude towards mobile health apps, provided that the criteria mentioned above can be met and that apps can solve the problem of human doubt about new technology. Technology is constantly evolving and integrating into our daily lives. As a result, a close relationship is developing more and more between people and these technologies. Patients need an algorithm that understands them better and makes fewer mistakes instead of understanding them perfectly and never making mistakes. Patients trust such an algorithm to make decisions about health and lifestyle choices (Harari, 2015). In summary, this research provided a better understanding of the underlying determinants that can predict the acceptance and intention of adoption of mobile health apps.

This work was supported by Help University, Grant: grant number 18-12-005

\section{References}

Ajzen T. (1991). The Theory of Planned Behavior. Organizational Behaviour and Human Decision Processes, 50, 179-211. https://doi.org/10.1016/0749-5978(91)90020-T

Albrecht UV. (2016). Chances and Risks of Mobile Health Apps (CHARISMHA). Available at: https://www.bundesgesundheitsministerium.de/fileadmin/Dateien/3_Downloads/A/App-Studi e/charismha_abr_v.01.1e-20160606.pdf(accessed 11 August 2018).

Alloghani M, Hussain A, Al-Jumeily D, \& Abuelma'atti O. (2015). Technology Acceptance Model for the Use of M-Health Services among Health Related Users in UAE. International Conference on Developments of E-Systems Engineering, 213-217. https://doi.org/10.1109/DeSE.2015.58

Athenahealth. (2018) Mobile Health Apps. Available at: https://www.athenahealth.com/knowledge-hub/mobile-health-technology/apps (accessed 8 August 2018).

Bagozzi RP., \& Yi Y. (1988). On the evaluation of structural equation models. Journal of the Academy of Marketing Science, 16(1), 74-94. https://doi.org/10.1007/BF02723327 


\section{NI Macrothink}

Journal of Management Research

ISSN 1941-899X

2019, Vol. 11, No. 3

Beldad A., \& Hegner S. (2017). Expanding the Technology Acceptance Model with the Inclusion of Trust, Social Influence, and Health Valuation to Determine the Predictors of German Users' Willingness to Continue using a Fitness App: A Structural Equation Modeling Approach. International Journal of Human-Computer Interaction, 1-12. https://doi.org/10.1080/10447318.2017.1403220

Churchill Jr GA (1979) A Paradigm for Developing Better Measures of Marketing Constructs. Journal of Marketing Research, 16(1), 64-73. https://doi.org/10.1177/002224377901600110

Churchill Jr G.A., \& Peter J.P. (1984). Research Design Effects on the Reliability of Rating Scales: A Meta-analysis. Journal of Marketing Research, 21, 360-375. https://doi.org/10.1177/002224378402100402

Cohen J. (1988). Statistical Power Analysis for the Behavioral Sciences (2nd ed.). Hillside, NJ: Lawrence Erlbaum Associates.

Davis F.D. (1989). Perceived Usefulness, Perceived Ease of Use, and User Acceptance of Information Technology. MIS Quarterly, 13(3), 319-340. https://doi.org/10.2307/249008

Deng Z, Zhang L, \& Zhang J. (2012). Applying technology acceptance model to explore the determinants of mobile health service: from the perspective of public user. Eleventh Wuhan International Conference on E-business, 406-411.

Dou L, Yu P, Deng N et al. (2017). Patients' Acceptance of Smartphone Health Technology for Chronic Disease Management: A Theoretical Model and Empirical Test. JMIR Mhealth Uhealth 5(12), 177. https://doi.org/10.2196/mhealth.7886

Faqih KMS., \& Jaradat MIRM. (2015). Mobile Healthcare Adoption among Patients in a Developing Country Environment: Exploring the Influence of Age and Gender Differences. International Business Research, 8(9). https://doi.org/10.5539/ibr.v8n9p142

Fishbein M., \& Ajzen I. (1975). Belief, Attitude, Intention and Behavior: An Introduction to Theory and Research. Addison-Wesley, Reading, MA.

Gold AH, Malhotra A., \& Segars AH. (2001). Knowledge management: an organizational capabilities perspective. Journal of Management Information Systems, 18(1), 185-214. https://doi.org/10.1080/07421222.2001.11045669

Grudin J. (1992). Utility and usability: research issues and development contexts. Interacting with Computers, 4(2), 209-217. https://doi.org/10.1016/0953-5438(92)90005-Z

Gruessner V. (2015). The Advantages of Mobile Health Apps Today and Tomorrow. Available at:

https://mhealthintelligence.com/news/the-advantages-of-mobile-health-apps-today-and-tomor row (accessed 20 August 2018).

Hair JF, Hult GTM, Ringle CM., \& Sarstedt M. (2014). Partial least squares structural equation modeling (PLS-SEM): An emerging tool in business research. European Business Review, 26(2), 106-121. https://doi.org/10.1108/EBR-10-2013-0128 


\section{Al Macrothink}

Journal of Management Research

ISSN 1941-899X

2019, Vol. 11, No. 3

Hanrahan C, Aungst TD., \& Cole S. (2014). Evaluating Mobile Medical Applications. United States: American Society of Health-System Pharmacists.

Harari YN. (2015). Homo Deus: A Brief History of Tomorrow. London: Random House.

Harrison R, Flood D., \& Duce D. (2013). Usability of mobile applications: Literature review and rationale for a new usability model. Journal of Interaction Science, 1(1), 1-16. https://doi.org/10.1186/2194-0827-1-1

Henseler J, Ringle CM., \& Sarstedt M. (2014). A new criterion for assessing discriminant validity in variance-based structural equation modeling. Journal of the Academy of Marketing Science, 43(1), 115-135. https://doi.org/10.1007/s11747-014-0403-8

Hung MC., \& Jen WY. (2012) The adoption of mobile health management services: an empirical study. J Med Syst, 36(3), 1381-1388. https://doi.org/10.1007/s10916-010-9600-2

Jones N., \& Moffitt M. (2016). Ethical guidelines for mobile app development within health and mental health fields. Professional Psychology: Research and Practice, 47(2), 155-162. https://doi.org/10.1037/pro0000069

Kang S. (2014). Factors influencing intention of mobile application use. Int. J. Mobile Communications, 12(4), 360-379. https://doi.org/10.1504/IJMC.2014.063653

Kline RB. (2011). Principles and practice of structural equation modeling. New York: Guilford Press.

Krebs P., \& Duncan DT. (2015). Health App Use Among US Mobile Phone Owners: A National Survey. JMIR mHealth and uHealth, 3(4), 101. https://doi.org/10.2196/mhealth.4924

Legris P, Inghamb J. \& Collerette P. (2003). Why do people use information technology? A critical review of the technology acceptance model. Information and Management, 40, 191-204. https://doi.org/10.1016/S0378-7206(01)00143-4

Müller O. (2013). Drivers in the Adoption of Mobile Health Applications. Master's thesis, Erasmus School of Economics, Netherlands.

Nasir S., \& Yurder Y. (2015). Consumers' and Physicians' Perceptions about High Tech Wearable Health Products. Social and Behavioural Sciences, 195, 1261 - 1267. https://doi.org/10.1016/j.sbspro.2015.06.279

Nielsen Global Survey. (2015). New Product Pioneers: Finding Early Adopters in Unexpected Areas. http://www.nielsen.com/my/en/insights/news/2015/new-product-pioneers-finding-early-adopt ers-in-unexpected-areas.html (accessed 30 September 2018).

Nor KM, Shanab EAA., \& Pearson JM. (2008). Internet banking acceptance in Malaysia based on the theory of reasoned action. Journal of Information Systems and Technology Management, 5(1), 3-14.

Peng W, Kanthawala S, Yuan S., \& Hussain S. (2016). A qualitative study of user perceptions 
of mobile health apps. BMC Public Health, 16(1). https://doi.org/10.1186/s12889-016-3808-0

Press Reader. (2018). Mobile Cellular Penetration Reaches 131.8\%. Available at: https://www.pressreader.com/malaysia/the-star-malaysia-starbiz/20180214/28151363661823 1 (accessed 18 August 2018).

Price MM, Pak R, Mu“ller H., \& Stronge A. (2012). Older adults' perceptions of usefulness of personal health records. Univ Access Inf Soc. https://doi.org/10.1007/s10209-012-0275-y

Ramayah T, Cheah J, Chuah F, Ting H., \& Memon MA. (2018). Partial Least Squares Structural Equation Modeling (PLS-SEM) using SmartPLS 3.0: An Updated and Practical Guide to Statistical Analysis (2nd ed.). Singapore: Pearson.

Research2Guidance. (2016). mHealth App Developer Economics 2016: The current status and trends of the mHealth app market. Available at: https://research2guidance.com/r2g/r2g-mHealth-App-Developer-Economics-2016.pdf (accessed 18 August 2018).

Research2Guidance. (2017). mHealth App Economics 2017/2018: Current Status and Future Trends in Mobile Health. Available at: https://research2guidance.com/wp-content/uploads/2017/11/R2G-mHealth-Developer-Econo mics-2017-Status-And-Trends.pdf (accessed 18 August 2018).

Ringle CM, Wende S., \& Will A. (2005). Smart PLS 2.0 M3. Hamburg: University of Hamburg.

Sun Y, Wang N, Guo X., \& Peng Z. (2013) Understanding the Acceptance of Mobile Health Services: A comparison and Integration of Alternative Models. Journal of Electronic Commerce Research, 14(2), 183-200.

Tomlinson M, Rotheram-Borus MJ, Swartz L., \& Tsai AC. (2013). Scaling up mHealth: where is the evidence? PLoS Med, 10(2). https://doi.org/10.1371/journal.pmed.1001382

Venkatesh V, Morris MG, Davis GB., \& Davis FD. (2003). User Acceptance of Information Technology: Toward a Unified View. MIS Quarterly, 27(3), 425-478. https://doi.org/10.2307/30036540

Yasini M., \& Marchand G. (2015) Mobile Health Applications, in the Absence of an Authentic Regulation, Does the Usability Score Correlate with a Better Medical Reliability? MEDINFO 2015: eHealth-enabled Health: 127-131.

Zahra F, Hussain A., \& Mohd H. (2017) Usability evaluation of mobile applications; where do we stand? AIP Conference Proceedings, 1891. Malaysia: AIP Publishing. https://doi.org/10.1063/1.5005389 